\title{
Interseccionalidade e violência contra as mulheres em tempos de pandemia de covid-19: diálogos e possibilidades
}

\section{Intersectionality and violence against women in covid-19 pandemic times: dialogues and possibilities}

\author{
Jeanine Pacheco Moreira Barbosa ${ }^{\mathrm{a}}$ \\ (D) https://orcid.org/0000-0003-1024-4378 \\ E-mail: jeaninepacheco®yahoo.com.br \\ Rita de Cassia Duarte Lima ${ }^{a}$ \\ (i) https://orcid.org/0000-0002-5931-398X \\ E-mail: ritacdløgmail.com \\ Gabriela de Brito Martins Santos ${ }^{a}$ \\ (D) https://orcid.org/0000-0003-1274-3664 \\ E-mail: brito.gabbyळgmail.com

\section{Solange Drumond Lanna ${ }^{a}$} \\ (D) https://orcid.org/0000-0002-2833-6740 \\ E-mail: nuprevi.vitoria®yahoo.com.br

\section{Maria Angélica Carvalho Andrade ${ }^{b}$} \\ (D) https://orcid.org/0000-0002-3690-6416 \\ E-mail: geliandradeळgmail.com \\ aUniversidade Federal do Espírito Santo. Vitória, ES, Brasil. \\ bUniversidade Federal do Espírito Santo. Departamento de \\ Medicina Social. Vitória, ES, Brasil.
}

\section{Correspondência}

Jeanine Pacheco Moreira Barbosa

Av. Marechal Campos, I.468. Vitória, ES, Brasil. CEP 29075-910.

\section{Resumo}

Este ensaio tem como objetivo problematizar as relações entre a violência contra as mulheres e o isolamento social durante a pandemia de covid-19, a partir do diálogo entre os aportes teóricos dos estudos interseccionais e as contribuições do Movimento Institucionalista, por meio da filosofia da diferença de Gilles Deleuze. O isolamento social na pandemia comparece como operador de análise e categoria de intersecção, o que pode ser compreendido como acontecimento no contexto do institucionalismo. Trata-se, portanto, de vislumbrar a interseccionalidade a partir de uma perspectiva pós-estruturalista. Busca-se viabilizar a construção de espaços de problematização, a partir das contribuições que vão desde a saúde até as ciências sociais e humanas, campo extenso e diversificado da saúde coletiva, refletindo a própria concepção ampliada de saúde em suas inúmeras interfaces. Por meio dessa perspectiva, buscou-se deslocar a relação de causalidade direta entre o isolamento social e violência contra as mulheres, fazendo uma análise sócio-histórico-política que articule o microssocial, singular, com o contexto macrossocial, a fim de descortinar desigualdades e violências já experimentadas.

Palavras-chave:Violência contra a Mulher; Violência Doméstica; Interseccionalidade; Pandemias. 
This essay aims at problematizing the relations between violence against women and social isolation during the covid-19 pandemic, based on the dialog between the theoretical contributions of the intersectional studies and those of the Institutionalist Movement by Gilles Deleuze's philosophy of difference. Social isolation in the pandemic appears both as an analysis operator and as an intersection category, which can be understood as an event in the context of institutionalism. This means, therefore, to envision intersectionality from the post-structuralist perspective. This study sought to construct problematization spaces based on contributions of Collective Health, which go from health to social and human sciences, reflecting on the amplified conception of health and its several different interfaces. From this perspective, the direct causal relationship between social isolation and the violence against women was displaced in a socialhistorical-political analysis that articulates the singular micro-social and the macro-social contexts, to unveil the inequalities and violence already experienced.

Keywords: Violence Against Women; Domestic Violence; Intersectionality; Pandemics.
Eu decidi que é melhor gritar... [...] O silêncio é o verdadeiro crime contra a humanidade. (Mandelstam, 1983, p. 42, tradução nossa)

A violência contra a mulher é um fenômeno que tem ganhado grande repercussão nacional e mundial no contexto de pandemia da covid-19, que afeta a todos, mas tem afetado diferentes grupos de pessoas, de distintas maneiras, aprofundando as desigualdades existentes. Dados iniciais indicam que a pandemia tem consequências sociais e econômicas devastadoras para mulheres e meninas, podendo, inclusive, reverter o progresso limitado feito na igualdade de gênero e nos direitos das mulheres (UN, 2020).

Desde a introdução de medidas de isolamento social para impedir a propagação da covid-19, quatro bilhões de pessoas em todo o mundo estão se abrigando em casa (UN, 2020). Com grande parte do mundo sob quarentena, começa-se a ouvir que um dos efeitos da pandemia é o aumento na violência contra as mulheres, especialmente a violência doméstica perpetrada por parceiros íntimos, pois muitas mulheres agora estão "presas" em casa com seus agressores (Violência..., 2020).

Ademais, o suporte social diminuiu com o fechamento de creches, estabelecimentos de ensino e religiosos, e restrição ou redução de jornada de trabalho nos serviços de proteção à mulher, como delegacias e centros de referência à violência doméstica, ampliando o risco e as vulnerabilidades de muitas mulheres (Machado et al., 2020; Marques et al., 2020). Na saúde, as Unidades Básicas de Saúde - sobretudo em comunidades mais vulneráveis - e os hospitais têm priorizado os casos de covid-19, o que pode gerar uma carência no atendimento a outras questões, como o acompanhamento de grávidas e portadoras de doenças crônicas.

Esses dados têm gerado uma preocupação constante entre pesquisadores(as) da saúde, como também de outras áreas. Contudo, alguns estudos e referências midiáticas, vistos de forma fragmentada, podem sugerir que o aumento da violência contra a mulher se deve à pandemia, numa relação direta de causalidade, esvaziando toda e qualquer análise 
de uma perspectiva sócio-histórico-política das questões que envolvem a violência de gênero. Entende-se história como o passado que está vivo no presente e pode estar, se já não está, determinando o futuro, lançando-se um olhar que toma a história não como uma repetição de fatos, mas como uma reconstrução a partir de novas perspectivas e acontecimentos (Baremblitt, 1996). As violências têm historicidade e têm se manifestado das mais variadas formas. Historicamente, as barreiras impostas pelas desigualdades raciais e de gênero têm sido determinantes no processo saúde-doençacuidado das mulheres, particularmente das mulheres negras (Goes; Nascimento, 2012).

A partir desse olhar, este ensaio, realizado no âmbito da saúde coletiva, busca romper com o monopólio do discurso biomédico ao mesmo tempo em que faz uma crítica à generalização do saber cientificista, fazendo uma aproximação com as ciências sociais e humanas para auxiliar na compreensão dos problemas que estejam além dos limites de cada "campo disciplinar", como o fenômeno da violência contra a mulher.

Quando se trata a violência contra as mulheres a partir de modelos estanques e homogeneizantes, que não consideram o processo de historicização das violências de gênero e as singularidades envolvidas, corre-se o risco de gerar verdades totalizantes, pautadas em binarismos e fragmentações. Dessa forma, muitas dessas mulheres poderiam ser silenciadas ou emudecidas por discursos cientificistas, acadêmicos e midiáticos, atravessados por posicionamentos cheios de certezas e ideias generalizantes, fontes de estigmatizações e preconceitos.

Nesse momento desafiador, faz-se necessário descrever essa realidade complexa, o que inclui reconhecer as várias formas de opressão feminina e suas vulnerabilidades agregadas, de modo a interrogar as diversas dimensões que atravessam as mulheres durante a pandemia de covid-19. Busca-se escapar dos discursos essencialistas e das afirmações universalistas que aprisionam as mulheres em modelos estruturados, que podem acabar por justificar a discriminação e violência de que são alvo em função de uma "essência feminina".

Nesse sentido, aposta-se nos referenciais da interseccionalidade, que remontam às origens do movimento feminista negro, para trazer importantes contribuições e dar visibilidade aos processos identitários a partir de uma análise que não se restrinja à soma de características e identificação de marcadores de grupos específicos e de identificação, mas que capture o caráter processual e dinâmico que muitas vezes encontra-se invisibilizado nos discursos de diversidade e pluralidade, que podem gerar o não pertencimento por parte de muitas mulheres oriundas de um mesmo grupo.

Ressalta-se que, neste ensaio, a interseccionalidade é compreendida a partir dos estudos de Kimberle Crenshaw, Patricia Hill Collins, Suzanne Knudsen, entre outras autoras, como uma teoria que analisa de que forma "as categorias sociais e culturais se entrelaçam. As relações entre gênero, raça, etnia, deficiência, sexualidade, classe e nacionalidade são examinadas em vários níveis, com o intuito de explicar as diversas desigualdades que existem na sociedade" (Knudsen, 2006, p. 61).

À análise pautada nos estudos interseccionais propõe-se a agregar o referencial do Movimento Institucionalista (MI), ou Institucionalismo, nascido na França, nas décadas de 1950 e 1960, expresso por vários movimentos que propuseram rupturas objetivas e subjetivas a uma lógica identitária e verticalizada presente nas instituições, buscando valorizar a diferença e a singularidade a partir de uma concepção relacional de poder, não hierárquica. Para este ensaio, serão utilizadas, sobretudo, as contribuições dos estudos de Gilles Deleuze, com a filosofia da diferença, e de Gregório Baremblitt. Além de criticar um conhecimento universal centralizado e dominado pela figura do expert, que aliena as pessoas da possibilidade de gerenciar as suas próprias vidas, o MI questiona a existência de um sujeito único e imutável em todas as sociedades e denuncia que não existem demandas ou necessidades naturais, uma vez que são produzidas pelos interesses dominantes. Seu foco está nos processos de subjetivação que geram subjetividades livres - revolucionárias e inauguradoras da diferença - ou sujeitadas, que, inconscientemente, submetem seu desejo aos organismos reprodutores, como o Estado e o mercado capitalista, resultando na repetição (Baremblitt, 1996).

A diversidade, pluralidade e singularidade são o foco da filosofia da diferença, além da dissolução das fronteiras entre sujeito e objeto que estão em constante 
relação, transformação e (re)criação. Deleuze (1998) propõe uma filosofia que não seja universal, nem com totalidade composta por partes isoladas, e defende a renovação do pensamento a partir da arte. Adiferença está em si: o diferenciar-se da própria coisa, ou seja, não se trata de reduzir a diversidade a um elemento comum entre as partes, trata-se de pensar a diferença como multiplicidade e criação, puro acontecimento.

Diante disso, no lugar de adotar o termo "violência contra mulher", que generaliza, reduz e limita, faz-se necessário pensar em "violência contra as mulheres", que permite a visibilidade de várias singularidades, multiplicando sentidos, estabelecendo uma relação rizomática, horizontalizada, fluxos em movimentos, em um devir mulher em constante transformação diante dos encontros com outros (pessoas e acontecimentos) (Barbosa, 2020).

Para o Institucionalismo, a melhor política pública só se efetivará se houver adesão de todos os sujeitos. Por isso, a partir desse referencial é possível criar campos de leitura para descrever a dinâmica que atravessa as mulheres de forma não hierárquica e não linear, tomando a pandemia como acontecimento, ou seja, "um momento de aparição do novo absoluto, da diferença e da singularidade” (Baremblitt, 1996, p. 146).

Assim, considerando nossa trajetória e implicação com a temática, e reconhecendo as diversas possibilidades e limites teóricos, neste ensaio aposta-se no diálogo entre os referenciais da interseccionalidade e do Institucionalismo na abordagem de um tema pouco explorado na saúde, que pode contribuir para possíveis ações de prevenção e promoção da saúde da mulher em situação de violência que articulem o local singular (microssocial) - com as representações e formas instituídas em um contexto mais amplo - social (macrossocial) -, favorecendo a análise das implicações sócio-histórico-políticas pelo coletivo.

Por essa via, focalizam-se as mulheres que assumem posicionamentos nessas intersecções, recuperando-as como sujeitos dos múltiplos emaranhados nesses em-com-outros. Desse modo, o isolamento social na pandemia comparece como operador de análise e categoria de intersecção, o que, no contexto do Institucionalismo, pode ser compreendido como acontecimento. Trata-se, portanto, de vislumbrar a interseccionalidade ensejada na perspectiva pósestruturalista (Ferraz; Tomazi; Sessa, 2019).
Nesse aporte, este ensaio tem como objetivo problematizar as relações entre a violência contra as mulheres e o isolamento social durante a pandemia de covid-19, entendido como acontecimento a partir da interlocução entre as contribuições dos estudos interseccionais e do MI, por meio da filosofia da diferença de Gilles Deleuze, a fim de descortinar desigualdades e violências já experimentadas.

\section{Violência contra as mulheres: interseccionalidades e diferenças}

Ser negro sem ser somente negro, ser mulher sem ser somente mulher, ser mulher negra sem ser somente mulher negra. (Carneiro, 2011)

A interseccionalidade na sua interface com os referenciais do Institucionalismo é proposta neste ensaio como fio condutor para a análise da opressão feminina que atravessa a violência contra as mulheres. Tal perspectiva conduz à reflexão de como os eixos de opressão se entrecruzam e potencializam, uma vez que, do ponto de vista analítico, permite identificação dos problemas sociais, capturando suas consequências estruturais e dinâmicas das complexas intersecções entre os vários eixos de subordinação, buscando desnaturalizar o instituído (constituído).

Os estudos de interseccionalidade ganharam notoriedade a partir das formulações feministas de Crenshaw, nas décadas de 1970 e 1980, surgidos como aparato teórico que buscou focalizar e valorizar os posicionamentos de mulheres negras nas leis e movimentos de direitos civis nos Estados Unidos, questionando a universalidade do patriarcado como sistema de dominação e trazendo um consenso de que os direitos humanos das mulheres não deveriam se limitar às situações em que os seus problemas se parecessem aos vivenciados pelos homens, o que encobria as experiências corporais e sexuais das mulheres negras, marginalizando-as como mulheres e reduzindo-as à sua raça. Essa noção de interseccionalidade remete às dimensões de empoderamento e desempoderamento, sendo este último referido à maneira pela qual o racismo, as relações patriarcais, a opressão de classe e outros eixos possíveis de poder e discriminação 
criam desigualdades (Assis, 2018; Costa, 2013; Crenshaw, 2002; Ferraz; Tomazi; Sessa, 2019).

Apesar da relevância dos trabalhos de Crenshaw, é importante salientar a delicada tarefa de se traçar as origens e as influências dos estudos de interseccionalidade, uma vez que não se trata de um campo homogêneo, além do fato de que essa reflexão se iniciou e tem sido (re)significada por várias autoras importantes do movimento feminista negro (Moutinho, 2014).

Mesmo tendo sido consagrados há mais de três décadas, alguns autores afirmam que os estudos sobre a interseccionalidade dão a impressão de que 'todos' realizam um trabalho interseccional, embora haja pouco consenso sobre o que a interseccionalidade realmente significa (Ferraz; Tomazi; Sessa, 2019).

O sentido de interseccionalidade para este ensaio é entendido a partir de uma metáfora de encontro de avenidas, onde os vários eixos de poder - isto é, raça, etnia, gênero e classe - constituem as vias que estruturam os terrenos sociais, econômicos e políticos, e é através delas que as dinâmicas do desempoderamento se movem. De acordo com Crenshaw, "as mulheres racializadas frequentemente estão posicionadas em um espaço onde o racismo ou a xenofobia, a classe e o gênero se encontram. Por consequência, estão sujeitas a serem atingidas pelo intenso fluxo de tráfego em todas essas vias" (Crenshaw, 2002, p. 177).

Segundo dados do Ligue 18o, a quarentena recomendada por governos estaduais e municipais como forma de conter a propagação da covid-19 provocou um aumento de aproximadamente $9 \%$ no número de ligações para o canal que recebe denúncias de violência contra a mulher. A Ouvidoria Nacional de Direitos Humanos, do Ministério da Mulher, da Família e dos Direitos Humanos, relata que a média diária entre os dias 1 e 16 de março de 2020 foi de 3.045 ligações recebidas e 829 denúncias registradas, contra 3.303 ligações recebidas e 978 denúncias registradas entre os dias 17 e 25 do mesmo mês (Coronavírus..., 2020).

Dados da Secretaria de Segurança de São Paulo, divulgados em 15 de abril de 2020, evidenciam que os assassinatos de mulheres em casa dobraram na capital do estado durante a quarentena. Além disso, um levantamento realizado pelo Ministério Público de São Paulo mostrou que os pedidos de medidas protetivas de urgência feitas pelas mulheres aumentaram $29 \%$ no mês de março em comparação com o mês de fevereiro do mesmo ano. Além disso, o número de prisões em flagrante por violência contra a mulher (homicídio, ameaça, constrangimento ilegal, cárcere privado, lesão, estupro etc.) também aumentou de 177 no mês de fevereiro para 268 em março de 2020. Nesse contexto, chama a atenção a redução no número de inquéritos policiais e processos nesse período, porque os prazos na justiça, em princípio, estavam suspensos até o fim de abril de 2020 (FBSP, 2020).

Esses dados geram ruídos que provocam incômodos e podem legitimar a compreensão de que a violência contra a mulher é uma resposta natural e normal para os momentos de crise. Por isso, considera-se importante o esforço para dialogar com as interseccionalidades e as diferenças, a partir da problematização do fenômeno da violência contra as mulheres em tempos de pandemia que permita uma análise capaz de religar os conhecimentos fragmentados, fazendo ressoar algumas perguntas: de que mulheres tratam os dados divulgados? Quais mulheres estão expressando a vivência dessa violência? Quais cotidianos estão imersos em constantes conflitos? Seria a pandemia responsável pela violência e seu aumento?

Destaca-se que, assim como a metáfora de encontro de vias remete a forças dinâmicas provenientes de diversas direções, o conceito de interseccionalidade também remete a um caráter dinâmico da discriminação e desempoderamento provocados por diversos eixos de poder. Portanto, categorias como raça, classe e gênero não podem ser categorias pensadas e analisadas isoladamente, elas são indissociáveis e interdependentes (Costa, 2013).

Um tema central a ser discutido dentro do debate da interseccionalidade é o significado de "mulher", que deve levar em conta fatores econômicos, políticos, culturais, físicos, subjetivos e de experiência. Nessa perspectiva, intersecção quer dizer multiplicidade e, na abordagem do "ser mulher", por exemplo, é imprescindível a consideração de questões de raça, orientação sexual, identidade de gênero, dentre outras, a fim de refutar a historiografia tradicional e a hierarquização de saberes (Ribeiro, 2017).

Ressalta-se o risco de se buscar uma unidade no "ser mulher", pois pode excluir corpos desviantes de um padrão instituído culturalmente e produzir 
apagamentos em relação a possíveis violências dentro do próprio campo dos feminismos, em função de outras violências que as mulheres podem sofrer, como aquelas relacionadas ao sexo, à classe, à raça, à pobreza, à saúde, entre outros marcadores bastante imbricados nas violências do Estado (Dell'Aglio; Machado, 2019; Werneck, 2016).

Faz-se ainda necessário, compreender o conceito de gênero para além da categorização binária, valorizando também as intersecções existentes entre os diversos marcadores (gênero, raça/cor, nível educacional, classe social, saúde, dentre outros), que só podem ser compreendidos de forma articulada nas interações entre as possíveis diferenças e desigualdades presentes em experiências sociais distintas, coletiva e individualmente.

Assim, quando se noticia que a violência aumentou em meio a um determinado grupo social durante a pandemia, é preciso refletir sobre como as complexidades intrínsecas às categorias se entrelaçam, buscando superar a dicotomia e a polarização, além de questionar de que ponto de vista parte a análise realizada, uma vez que a escrita e a fala são território de luta e resistência. Caso contrário, corre-se o risco de estigmatizar determinados grupos, invisibilizar singularidades, privatizar uma demanda que na verdade está imersa em um contexto muito maior e complexo, além de eximir a responsabilidade do Estado.

Ainterseccionalidade está diretamente conectada às reivindicações da população negra e de movimentos sociais, especialmente o Movimento de Mulheres Negras. Dentre elas, estão as referentes à saúde, ou seja, por mais e melhor acesso ao sistema de saúde, participando, inclusive, dos processos que geraram a Reforma Sanitária e a criação do Sistema Único de Saúde. No entanto, é possível verificar que essa presença, apesar de ter contribuído para a concepção e para a construção de um sistema público universal de saúde, tendo como principais diretrizes e princípios a igualdade, a integralidade, a equidade e a participação social, isso, por si só, "não foi suficiente para inserir, no novo Sistema, mecanismos explícitos de superação das barreiras enfrentadas pela população negra no acesso à saúde, particularmente aquelas interpostas pelo racismo" (Werneck, 2016, p. 536).

Afirma-se, portanto, a importância dos debates interseccionais no cenário atual, a partir do entendimento de que os marcadores "não são compreendidos isoladamente, nem se propõem a uma mera adição de discriminações, mas sim, abraça-se a complexidade dos cruzamentos dos processos discriminatórios e a partir daí se busca compreender as condições específicas que deles decorrem" (Kyrillos, 2020, p. 1).

$\mathrm{O}$ entrecruzamento entre gênero e demais condições, para este ensaio, são entendidos, portanto, como analisadores que nos permitem problematizar as vulnerabilidades e acolher as singularidades já que, pelo olhar da filosofia da diferença, entende-se essa problematização como uma busca de outros sentidos para a pandemia como acontecimento, e para a análise da violência contra as mulheres como um processo de produção de "linhas de fuga que desfazem as essências e as significações em proveito de uma matéria mais intensiva onde se movimentam os afetos" (Krahe; Matos, 2010, p. 5). É justamente a partir da visibilidade da expressão dessas singularidades que se pensou a diferença como possibilidade de estranhamento e de território de luta para questionar as produções de significados homogeneizantes e naturalizados na sociedade.

Em estudo realizado em um centro de referência à mulher em situação de violência no Espírito Santo, as profissionais afirmaram que a maioria das usuárias eram negras e pardas e justificavam esse dado pelo fato de que muitas delas eram chefes de família, tinham subempregos, residiam em bairros de baixa renda e possuíam pouca escolaridade, o que as deixava mais vulneráveis à violência. Esse exemplo pode sugerir uma relação de causalidade 'natural' entre a violência e a mulher negra, que seria sempre pobre e sem escolaridade, apagando as diversidades contidas nesses grupos, o que impede uma análise mais apurada dos mecanismos operadores de desigualdades na sociedade, como o patriarcado, o sexismo e o capitalismo (Barbosa, 2020).

Portanto, é preciso ressaltar que o gênero é constituído e representado de maneira diferente segundo a localização da mulher dentro de relações globais de poder - que se realiza por meio de processos econômicos, políticos e ideológicos -, e essas "diferenças" se articulam constantemente, mas não podem ser compreendidas como uma relação direta de uma a partir da outra, pois o significado atribuído 
a determinado evento é variável de um indivíduo para outro, ou seja, é singular (Brah, 2006). Nesse sentido, é importante perceber o gênero como categoria analítica relevante e a interseccionalidade como a perspectiva teórica que dialoga com as experiências subjetivas das mulheres em situação de violência no contexto da pandemia de covid-19 (López, 2013).

A partir desse entendimento, o cotidiano das relações sociais de gênero - desde o trabalho doméstico e o cuidado das crianças, empregos mal remunerados e dependência econômica, até a violência sexual e a exclusão das mulheres de centros-chave de poder político e cultural - ganhou novo significado à medida que deixou o domínio da verdade absoluta para ser interrogado e enfrentado (Brah, 2006).

Assim, o olhar institucionalista coaduna com os estudos interseccionais na medida em que a interseccionalidade é compreendida de forma rizomática, ou seja, estruturas em tramas que se ramificam, de forma não hierarquizada, como encruzilhadas, como ponto de contato entre linhas, elementos e categorias, como vetores e nódulos que se conectam e desconectam, e onde as intersecções concretas, as hierarquias e a elaboração não são predeterminadas, estando em constante mudança e variação de potência, refletindo seu caráter amorfo e expansivo (Ferraz; Tomazi; Sessa, 2019).

Na prática, a interseccionalidade lança olhares sobre o desafio de fazer emergir as consequências estruturais e dinâmicas da interação entre dois ou mais eixos da subordinação, que trata especificamente da forma pela qual o racismo, o patriarcalismo, a opressão de classe e outros sistemas discriminatórios criam desigualdades básicas e estruturam as posições relativas de mulheres, raças, etnias e classes, dentre outras (Assis, 2018).

Nesse sentido, destaca-se a necessidade de não se homogeneizar as questões referentes às mulheres, particularmente as negras, uma vez que essa é uma categoria diversa e diz respeito ao modelo de sociedade que se busca construir.

Com relação à vinculação entre racismo e vulnerabilidades, Carneiro (2011) aponta que:

a utopia perseguida pela mulher negra consiste em buscar um atalho entre uma negritude redutora da dimensão humana e a universalidade ocidental hegemônica que anula a diversidade [...]. Alcançar a igualdade de direitos é converter-se em um ser humano pleno e cheio de possibilidades e oportunidades para além de sua condição de raça e de gênero. Esse é o sentido final dessa luta.

Nesse âmbito, cabe ressaltar, em um contexto de pandemia, para além do isolamento social, que é preciso pensar no isolamento histórico de mulheres, que vem sofrendo múltiplas violências, invisibilidades através do tempo, com raízes na produção de subjetividades assujeitadas ao modo de produção capitalista (Baremblitt, 1996).

Assim, dependendo do contexto, a noção de interseccionalidade pode ser utilizada não somente para analisar efeitos advindos da opressão e do desempoderamento, mas também para analisar a mobilização política (Costa, 2013).

Apesar das enormes contribuições dos estudos interseccionais, Moutinho (2014, p. 201) alerta que é preciso "entender a lógica das sujeições combinadas reinantes nas análises como um processo de construção e nomeação: a construção de sujeitos e a nomeação de formas de exclusão são parte desse cenário de fazer políticas e construir direitos”.

Diante disso, busca-se ampliar a perspectiva interseccional, dialogando com as contribuições da filosofia da diferença, apostando nos processos de produção de subjetividade livre e revolucionária, num esforço para desvelar as diferentes vivências das mulheres durante a pandemia, em meio a uma sociedade atravessada pelo capitalismo, pelo racismo e pelo sexismo, dentre outros marcadores, sem que essa análise se restrinja a uma mera sobreposição de opressões, gerando ruídos que podem vir a silenciar as vozes dos sujeitos envolvidos.

\section{A pandemia como acontecimento e disparador de análise: ruídos e silêncios}

Não perguntaremos, pois, qual é o sentido de um acontecimento: o acontecimento é o próprio sentido.

(Deleuze, 2015, p. 23)

A violência contra as mulheres não surge com a pandemia e, segundo a Organização Mundial de 
saúde (OMS), suas causas estão alicerçadas em fatores histórico-sociais, tais como a desigualdade de gênero, econômica, machismo estrutural entre outros (OMS, 2012). Ao considerar o aumento da violência contra as mulheres, especialmente a violência doméstica, como um dos efeitos da pandemia, corre-se o risco de privatizar um problema social. O isolamento social por si só não ocasiona a violência, mas tem a potência de colocar em evidência as vivências dessas mulheres, dando ênfase às desigualdades historicamente construídas e naturalizadas.

Os estudos interseccionais contribuíram e continuam contribuindo para 'fazer ouvir' os ruídos que envolvem a violência contra as mulheres. Contudo, tão importante quanto descrevê-los é o questionamento sobre o que esses ruídos abafam e silenciam: como a violência atinge as diferentes mulheres no país? Por que a violência se faz habitual em alguns corpos mais do que em outros? A violência doméstica estaria restrita a uma determinada raça/etnia e/ou classe social? Por que razão isso se dá? Como os diversos marcadores/intersecções afetam a produção de subjetividade no contemporâneo? Se os dados preliminares indicam um aumento da violência contra as mulheres durante a pandemia, o que se pode "ler" ou "escutar" sobre esse fenômeno tomando a pandemia como acontecimento e não como causa direta? Que consequências essa leitura pode ter sobre as políticas públicas relacionadas à violência contra as mulheres? Essas serão as possíveis contribuições ao agregarmos os referenciais institucionalistas.

Articulando os estudos interseccionais e a filosofia da diferença, a pandemia não estabelece uma relação de causalidade para o aumento da violência contra a mulher, mas efetiva-se como um analisador, um acontecimento que evidencia um campo de disputa de forças, entre o microssocial e o macrossocial, tornando visível aquilo que é naturalizado pelas instituições para que, dessa forma, seja possível colocá-lo em análise.

Diante disso, lança-se um olhar para a pandemia como acontecimento, tomando-a como analisador, capaz de fazer emergir questões naturalizadas no campo de forças constituído entre a pandemia e a violência contra as mulheres. Segundo Rodrigues, Leitão e Barros (1992, p. 42), um analisador é:

um acontecimento ou movimento social, que vem ao nosso encontro, inesperadamente, condensando uma série de forças, até então dispersas. Nesse sentido, realiza a análise por si mesmo, a maneira de um catalizador químico de substâncias.

Para Deleuze (2015), o acontecimento é sempre problemático, problematizante, pois indaga, questiona e inquieta. Escrever, pensar, não é representar realidades, mas sim, produzir realidades, intervir na realidade, transformando-a e singularizando-a. O sentido perpassa por três planos, seguindo primeiro por uma designação, que se refere a conceitos, nomes e enunciações, sobretudo quando falamos dos diversos marcadores e da evolução de conceitos, reconhecendo o processo dinâmico de ressignificação das intersecções. Nesse processo de reconceitualização da pandemia enquanto acontecimento, é importante considerar a inclusão e a nomeação da violência contra as mulheres como uma prática estrutural, préexistente, que é desvelada diante do acontecimento da pandemia, contribuindo para a desnaturalização do pensamento que associa a violência como resposta direta à crise sanitária instalada. É necessário e desafiador reconhecer a violência contra as mulheres como uma pandemia não visível, que age nas sombras e nos silêncios em meio à covid-19, e garantir que seus direitos sejam respeitados, fatores essenciais para fortalecer os esforços de prevenção, resposta e recuperação (Violência..., 2020).

Depois, o sentido revela-se como manifestação, evidenciando desejos, crenças e valores de base. Nesse plano, os indicadores de 'aumento' da violência contra as mulheres em tempos de pandemia precisam ser questionados, uma vez que a construção, o uso e a análise de indicadores de violência são atravessados pelo uso político que se faz da categoria e dos discursos sobre o fenômeno da violência, segundo contextos sociais distintos.

Nesse contexto, destaca-se a existência da subnotificação crônica das formas de violência doméstica, anterior à covid-19, onde menos de 40\% das mulheres em situação de violência buscavam qualquer tipo de ajuda ou denunciavam o crime e, 
destas, menos de $10 \%$ das mulheres procuravam ajuda policial. O contexto atual da pandemia, com maiores limitações no acesso de mulheres a telefones e linhas de ajuda e interrupção e/ou diminuição dos serviços públicos como polícia, justiça e serviços sociais, tem apontado para a existência de maiores discrepâncias na situação atual estimada das mulheres em situação de violência doméstica (Violência..., 2020).

Por último, o sentido aparece no plano do não senso, da significação, que é outro, é encontro de corpos produzindo movimento, percepção e afetos, e criando vias de vibração e singularidades. A partir dessa ideia é possível refletir sobre a dificuldade que a sociedade tem de acolher as singularidades ou aquelas mulheres que "escapem" dos padrões estabelecidos, pois elas representam um desafio para a manutenção do status quo que está a serviço dos meios de produção. Quando a sociedade não consegue incorporar esses padrões desviantes transformando-os em mercadorias a partir de uma lógica dos sistemas, resolve então deixálos morrer ou matá-los por meio de mecanismos construídos de formas mais ou menos deliberadas. Como resultado, surgem as guerras, violências contra as mulheres, desassistências e violências institucionais, preconceitos raciais/étnicos, dentre outros que se interpenetram nas políticas públicas que acabam por legitimar desigualdades.

Para o institucionalismo não existe um sujeito universal e imutável em todas as sociedades com apenas variações de desenvolvimento. 0 que existe são processos de produção de subjetividade que reproduzem ou não, sujeitos idênticos ou similares, segundo os padrões dominantes. Homens e mulheres entram nos processos sociais determinados por forças desejantes, modos de pensar/agir que não controlam e não conhecem (prazer, sofrimento) que são os mecanismos subjetivos profundos. Por meio desse mecanismo que impregna todas as instituições, os grandes organismos a serviço do Estado e do mercado capitalista capturam as forças desviantes, ou seja, mulheres que não se comportam de acordo com os modelos estabelecidos, por meio de uma antiprodução que resulta na destruição de tudo aquilo que é singular e novo. Essa reprodução do mesmo é uma das formas mais comuns da exploração capitalista que resulta na expropriação da potência de agir de cada mulher, impossibilitando a autogestão de sua própria vida (Baremblitt, 1996).

A experiência é, portanto, um conceito-chave para o entendimento das interseccionalidades, como também necessária para pensar a produção de analisadores que possam criar "linhas de fuga", ultrapassando a categorização binária do conceito de gênero e efetivando a diferença como marcador de distintividade entre as "histórias" coletivas e a experiência pessoal inscrita na biografia individual, por isso a crítica à generalização e a importância de se afirmar as singularidades. Assim, enunciar que as mulheres têm vivenciado um aumento da violência em tempos de pandemia não é suficiente para descrever as suas experiências, muito menos para estabelecer uma relação causal direta entre pandemia e violência. É preciso perguntar quem são e onde estão essas mulheres, a partir de uma análise interseccional, considerando-se como as diversas categorias relacionadas a elas e à violência doméstica constituem e são constituídas nas e pelas instituições e estruturas hegemônicas (Ferraz; Tomazi; Sessa, 2019).

Assim, quando se fala em interseccionalidade como produção de lugar de fala por um posicionamento epistemológico, um debate estrutural, coletivo, afirma-se aqui, mais do que experiências individuais, fala-se de condições sociais que permitem ou não que essas mulheres acessem lugares de cidadania e oportunidades (Ribeiro, 2017). Embora haja destaque para a dimensão opressiva, discriminatória e exploratória das relações de poder, faz-se necessário destacar também a dimensão de ativismo e mobilização política trazida pelo acesso à experiência como disparador de análise, que pode conduzir a formas democráticas de agenciamento político (Brah, 20o6).

Por isso, a abordagem deste ensaio parte da perspectiva da interlocução entre a interseccionalidade e a filosofia da diferença, em que se acolhem as contribuições de vários campos teóricos que se entrecruzam, favorecendo a abordagem transdisciplinar, rizomática, tão necessária aos estudos da Saúde Coletiva, privilegiando um olhar processual sobre a violência no contexto da pandemia (Figura 1). 


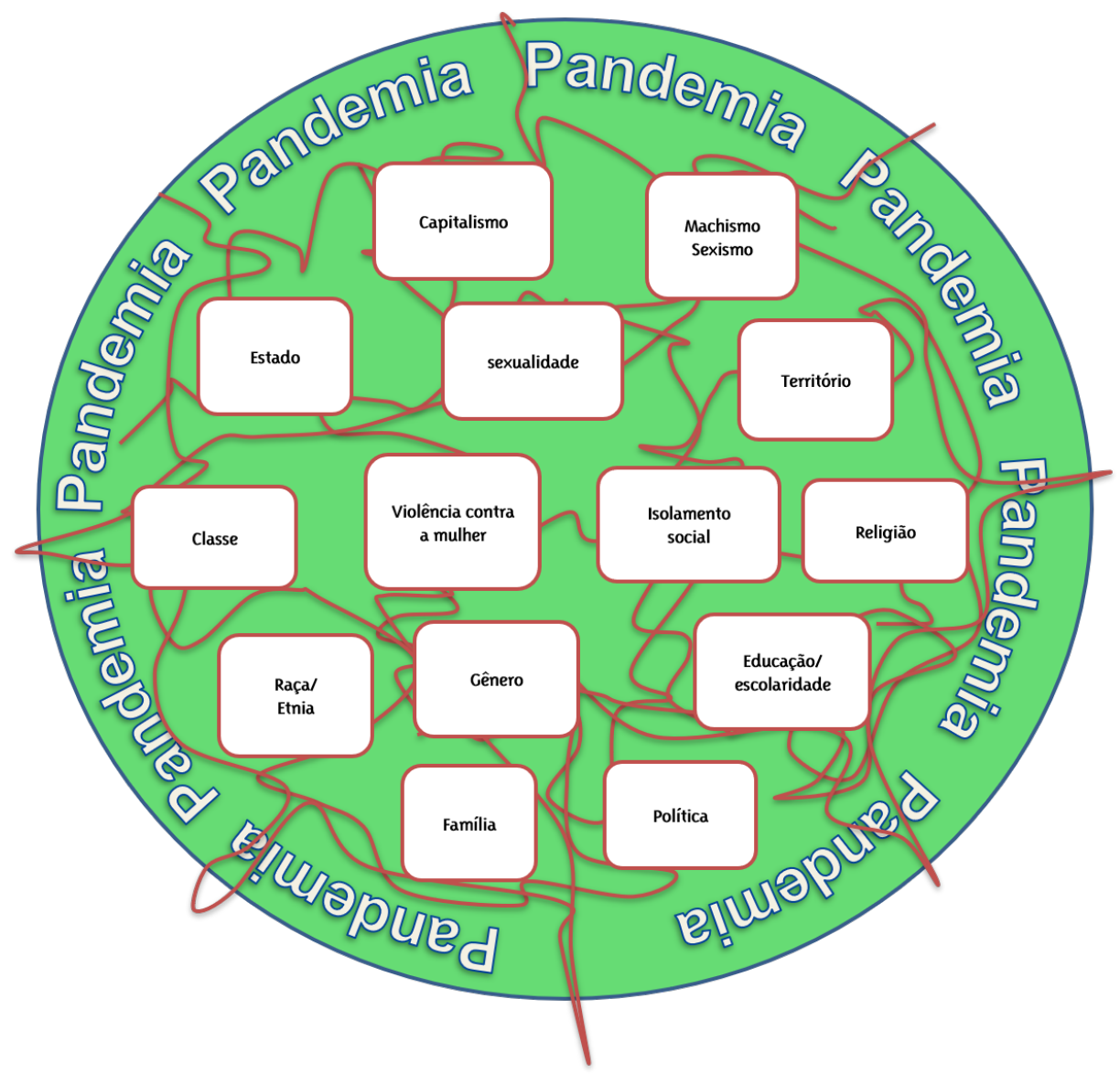

Fonte: Produção das autoras (2020)

Observando o campo de leitura apresentado, percebe-se que a valorização das diferenças aliada aos estudos interseccionais tem a potência de produzir investigações a partir de uma visão menos fixa e dicotômica em relação às diversidades. 0 que se propõe é um olhar que perceba a dinâmica de transformação dessas categorias, ao mesmo tempo em que transformam umas às outras e são transformadas. Dessa forma, cada uma delas se desestabiliza e o foco passa a ser o processo, no qual elas estão sendo, ou seja, estão se fazendo constantemente, ou como afirma Femenías (2013, p. 20), “a própria transformação se torna o objeto de análise, nos perguntando sobre o tipo de "sujeitos "ou " indivíduos " que teríamos que nos tornar a fim de habitar o mundo transformado".

Ressalta-se que, além de considerar os efeitos variados nos quais os múltiplos eixos de diferenciação se articulam em contextos historicamente específicos, o diálogo entre a interseccionalidade e o Institucionalismo permite visualizar ações políticas que podem gerar processos de desconstrução dessas desigualdades, ampliando as possibilidades de mudanças institucionais no sentido da promoção de igualdade racial e de gênero (Dell'Aglio; Machado, 2019).

$\mathrm{O}$ aumento da violência contra as mulheres aparece, por um lado, como analisador das práticas instituídas que silenciam as mulheres a partir da reprodução de subjetividades assujeitadas. Por outro lado, como manifestação dos processos de captura do sistema capitalista que cria modelos a serem seguidos pela sociedade, que acaba por naturalizar e privatizar esses processos de violência, gerando preconceitos e estigmatizações.

Dessa forma, os ruídos dessa pandemia tomada como acontecimento podem ser questionados na 
busca por um o foco que privilegie o processo, em que as diversas intersecções e atravessamentos se dão e se constituem. É necessário subverter as categorias de análise, buscando outros sentidos a partir da audição dos "silêncios" que desvelam violências naturalizadas, historicamente constituídas. Uma vez que a diferença é condição intrínseca à igualdade, é preciso dar passagem aos modos de ser/viver/agir que inaugurem o novo absoluto, a inventividade, acolhendo novos modos de vida.

\section{Considerações finais para possiveis (re)começos}

\section{[No] hay igualdad sin diferencia, ni diferencia sin igualdad. (Femenías, 2012, p. 152)}

A aposta deste artigo foi problematizar as relações entre a violência contra as mulheres e o isolamento social durante a pandemia de covid-19, a partir do diálogo entre os aportes teóricos dos estudos interseccionais e as contribuições do MI. Desse modo, o isolamento social na pandemia compareceu como operador de análise e categoria de intersecção, o que pode ser compreendido como acontecimento, no contexto do Institucionalismo, permitindo desnaturalizar o instituído.

A filosofia da diferença aponta para a construção de possibilidades interventivas, que inquietam e problematizam a realidade no sentido de romper com essa naturalização histórica da violência contra a mulher, dando passagem a uma ideia de mulher não como categoria fixa e acabada, mas em constante movimento e transformação, na medida em que os acontecimentos as afetam, as singularizam num devir-mulher, ou seja, um vir a ser, fluido que carrega a possibilidade de invenção de novas formas de ser/viver/agir.

A produção de novos sentidos para a pandemia, tomada como acontecimento, convoca a ir além de uma relação de causalidade ou segmentação de categorias, conduzindo a uma análise por linhas de fuga, que enfatiza a visibilidade e expressão de singularidades pelo estranhamento do que é posto, instituído. A possibilidade de articulação de lutas e resistências, por meio desses questionamentos e reflexões, rompe com aprisionamentos em imposições e naturalizações, abrindo outros caminhos para as produções de subjetividade no contemporâneo.

A partir dessa perspectiva foi possível descrever como o isolamento social, entendido como uma intersecção, tem afetado as mulheres sobre a violência que as oprime, pela separação das pessoas e dos recursos que podem ajudá-las no enfrentamento às situações de violência, mas, sobretudo pela (in)visibilidade histórica da violência doméstica propiciada pela sua ocorrência no espaço privado, legitimada pelas instituições, como o Estado, e ampliada durante a pandemia pela evidente diminuição da capacidade de resposta dos serviços essenciais de proteção às mulheres, o que pode vir a encobrir a magnitude dessa realidade. Por essa ótica, o isolamento social por si só não ocasiona a violência, mas quando tomado como acontecimento e analisador tem a potência de fazer emergir as singularidades apagadas pela generalização, desvelando como o machismo estrutural se configura na sociedade através da análise interseccional que leva em consideração os entrecruzamentos entre as categorias desigualdades raciais, de gênero e de classe social, oriundas das relações opressivas do sistema patriarcal, estruturado historicamente na sociedade brasileira.

Ao se pensar o fenômeno histórico da violência contra a mulher e sua agudização no contexto da pandemia de covid-19, a perspectiva teórica da interseccionalidade aliada ao Institucionalismo denunciam como a violência se organiza na sociedade patriarcal brasileira, abrindo passagem para processo de produção de subjetividades livres, potentes e revolucionárias construindo com e para as mulheres possibilidades outras de ser/viver/agir durante o distanciamento e isolamento social.

Destaca-se a importância da valorização das singularidades e da diferença, buscando entender como os diversos fluxos e avenidas interseccionais atravessam as mulheres em tempos de pandemia de covid-19. Ao lançar um olhar processual sobre o fenômeno da violência contra as mulheres e suas 
diversas intersecções que estão constantemente se reformulando, é possível arquitetar vias constantes de inauguração de novas possibilidades, mais criativas, permitindo à sociedade gerar possíveis (re)começos para homens e mulheres.

\section{Referências}

ASSIS, J. F. Interseccionalidade, racismo institucional e direitos humanos: compreensões à violência obstétrica. Serviço Social e Sociedade, São Paulo, n. 133, p. 547-565, 2018.

BARBOSA, J. (Des)tecendo a produção de cuidado à mulher em situação de violência. Rio de Janeiro: Bonecker, 2020.

BAREMBLITT, G. F. Compêndio de análise institucional e outras correntes: teoria e prática. Belo Horizonte: Instituto Félix Guattari, 1996.

BRAH, A. Diferença, diversidade, diferenciação. Cadernos Pagu, Campinas, n. 26, p. 329-376, 2006.

CARNEIRO, S. Enegrecer o feminismo: a situação da mulher negra na América Latina a partir de uma perspectiva de gênero. Geledés, São Paulo, 6 mar. 2011. Disponível: <https://bit.ly/3myVmc5>. Acesso em: 22 jul. 2020.

CORONAVÍRUS: sobe o número de ligações para canal de denúncia de violência doméstica na quarentena. Ministério da Mulher, da Família e dos Direitos Humanos, Brasília, DF, 27 mar. 2020. Disponível: <https://bit.ly/3myqQzo>. Acesso em: 13 abr. 2020.

COSTA, J. B. Controle de vida, interseccionalidade e política de empoderamento: as organizações políticas das trabalhadoras domésticas no Brasil. Estudos Históricos, Rio de Janeiro, v. 26, n. 52, p. 471-489, 2013.

CRENSHAW, K. Documento para o encontro de especialistas em aspectos da discriminação racial relativos ao gênero. Revista Estudos Feministas, Florianópolis, v. 10, n. 1, p. 171-188, 2002.

DELEUZE, G. Diferença e repetição. Rio de Janeiro: Graal, 1998.

DELEUZE, G. Lógica do sentido. São Paulo: Perspectiva, 2015 .
DELL'AGLIO, D. D.; MACHADO, P. S. Trajetórias e experiências: a construção do sujeito político feminista desde uma perspectiva interseccional. Revista Estudos Feministas, Florianópolis, v. 27, n. 2, e48556, 2019.

FBSP - FÓRUM BRASILEIRO DE SEGURANÇA PÚBLICA. Violência doméstica durante a pandemia de covid-19. São Paulo, 16 abr. 2020.

FEMENÍAS, M. L. Sobre sujeto y género: re-lecturas feministas desde Beauvoir a Butler. 2. ed. Rosario: Prohistoria Ediciones, 2012.

FEMENÍAS, M. L. La utopía feminista como transgresión. Aletria, Belo Horizonte, v. 23, n. 1, p. 11-22, 2013.

FERRAZ, D. M.; TOMAZI, M. M.; SESSA, A. As mortes de Matheusa em uma notícia do Estadão: estudos interseccionais sobre preconceito, discriminação e violência física em relação à diversidade de gêneros. Revista Brasileira de Linguística Aplicada, Belo Horizonte, v. 19, n. 4, p. 927-958, 2019.

GOES, E. R.; NASCIMENTO, E. R. Mulheres negras e brancas: as desigualdades no acesso e utilização dos serviços de saúde no estado da Bahia, PNAD - 2008. In: BATISTA, L. E.; WERNECK, J.; LOPES, F. (Org.). Saúde da população negra. 2. ed. Brasília, DF: ABPN, 2012. p. 274-287. (Coleção negras e negros: pesquisas e debates). Disponível em: <https://bit.ly/3dThbiE〉. Acesso em: 22 abr. 2020.

KNUDSEN, S. Intersectionality: a theoretical inspiration in the analysis of minority cultures and identities in textbooks. In: BRUILLARD, E. et al. (Ed.). Caught in the web or lost in the textbook? Caen: Iartem, 2006. p. 61-76.

KRAHE, I. B.; MATOS, S. R. L. Devir-mulher como diferença. In: CINFE - CONGRESSO INTERNACIONAL DE FILOSOFIA E EDUCAÇÃO, 5., 2010, Caxias do Sul. Anais... Caxias do Sul: Universidade de Caxias do Sul, 2010.

KYRILLOS, G. M. Uma análise crítica sobre os antecedentes da interseccionalidade. Revista Estudos Feministas, Florianópolis, v. 28, n. 1, e56509, 2020. Disponível em: <https://bit.ly/3dKooyA >.

Acesso em 15 abr. 2020. 
LÓPEZ, L. C. A mobilização política das mulheres negras no Uruguai: considerações sobre

interseccionalidade de raça, gênero e sexualidade. Sexualidad, Salud y Sociedad, Rio de Janeiro,

n. 14, p. 40-65, 2013.

MACHADO, D. F. et al. Violência contra a mulher: o que acontece quando a Delegacia de Defesa da Mulher está fechada? Ciência \& Saúde Coletiva, Rio de Janeiro, v. 25, n. 2, p. 483-494, 2020.

MANDELSTAM, N. Holpe against holpe: a memoir. New York: Atheneum, 1983.

MARQUES, E. S. et al. A violência contra mulheres, crianças e adolescentes em tempos de pandemia pela covid-19: panorama, motivações e formas de enfrentamento. Cadernos de Saúde Pública, Rio de Janeiro, v. 36, n. 4, eooo74420, 2020.

MOUTINHO, L. Diferenças e desigualdades negociadas: raça, sexualidade e gênero em produções acadêmicas recentes. Cadernos Pagu, Campinas, n. 42, p. 201-248, 2014.
OMS - ORGANIZAÇÃO MUNDIAL DA SAÚDE. Prevenção da violência sexual e da violência pelo parceiro íntimo contra a mulher: ação e produção de evidência. Brasília, DF: OMS: Opas, 2012.

RIBEIRO, D. O que é lugar de fala? Belo Horizonte: Letramento, 2017.

RODRIGUES, H. B. C.; LEITÃO, M. B. S.; BARROS, R. D. B. Grupos e instituições em análise. Rio de Janeiro: Rosa dos Tempos, 1992.

UN - UNITED NATIONS. Policy brief: the impact of covid-19 on women. New York: UN Women, 9 abr. 2020. Disponível em: <https://bit.ly/31Y7HgJ>. Acesso em: 14 jul. 2020.

VIOLÊNCIA contra mulheres e meninas é pandemia das sombras. Nações Unidas Brasil, Brasília, DF, 8 abr. 2020. Disponível em: <https://bit.ly/3mziln>. Acesso em: 13 abr. 2020.

WERNECK, J. Racismo institucional e saúde da população negra. Saúde e Sociedade, São Paulo, v. 25, n. 3, p. 535-549, 2016.

\section{Contribuição dos autores}

Todas as autoras conceberam e delinearam a pesquisa, redigiram o manuscrito, realizaram a revisão crítica e aprovaram a versão final do documento.

Recebido: $28 / 07 / 2020$

Aprovado: $14 / 10 / 2020$ 